\title{
Practice and Exploration of Quality Management System in Higher Vocational Colleges from a Perspective of ISO9001
}

\author{
Zhaojie Cao ${ }^{1,2}$ \\ ${ }^{1}$ Fushun Doctoral Workstation, Sichuan University of Sciences \& Engineering, Zigong, China \\ ${ }^{2}$ School of Education and Psychological Science, Sichuan University of Sciences \& Engineering, Zigong, China \\ Email address: \\ zjcao@suse.edu.cn
}

\section{To cite this article:}

Zhaojie Cao. Practice and Exploration of Quality Management System in Higher Vocational Colleges from a Perspective of ISO9001. International Journal of Vocational Education and Training Research. Vol. 7, No. 1, 2021, pp. 35-40. doi: 10.11648/j.ijvetr.20210701.16

Received: May 19, 2021; Accepted: May 31, 2021; Published: June 7, 2021

\begin{abstract}
Higher vocational colleges as the base for high-skilled talents cultivation, the quality of its graduates have attracted more attention from the society. The quality control is the critical factor for higher vocational colleges to improve their core competence. However, there are many overlapping funcations among administrative departments, which leads to unclear and unreasonable division of responsibilities due to its specific mechanism and system of higher vocational school. This reveals that the quality assurance in higher vocational colleges should be improved urgently under the background of China's high-quality development strategy. In order to provide a good education and improve education quality, higher vocational colleges need to change managing concept and improve inner management reform. Establishing a quality assurance system which complies with the ISO 9000 standards or total quality management will become an important base in achieving excellence for higher vocational colleges. This paper utilizes ISO9000 standard and the ISO14000 environmental management system to analyze factors for the total quality control in higher vocational colleges, establishes a complex quality management system from the perspectives of total quality management and improves effects of the quality on teaching and management.
\end{abstract}

Keywords: Total Quality Management System, ISO9000, Higher Vocational College

\section{Introduction}

Higher vocational colleges are social organizations of training applied professionals which play a vital role in the process of human civilization. History and reality endow them with special attributes and functions [1]. The quality of education attracts more people's attention, so it has become the basis for parents and students to choose higher vocational schools. The quality of education in higher vocational colleges is the comprehensive embodiment to run a school. When talking about the problems in school quality, it is always explained with education quality or teaching quality. The higher vocational colleges have the key features of high quality, characteristics and development in high-level construction. The cultivation of quality management has core strategic importance for it [2]. Under the background of the "14th Five-Year Plan", higher vocational colleges presented the developing direction of AI application, scenes of user experience, integration of skills and service, etc. Excellent higher vocational colleges have begun to improve schooling quality consciously, build quality management systems, carry out effective quality self-monitoring to ensure its stability and sustainability and meet the needs of society and competition.

This paper bases on the questioner about what is the current situation of teaching quality assurance in higher vocational colleges? What are the important factors that will influence the teaching quality? And whether the students are satisfied with the present teaching quality? According to the survey, a comprehensive education management system and some related countermeasures will be proposed to solve the current issues.

\section{Definition}

The introduction of ISO9000 International Quality Control Standard to educational field and Quality Management Systems established in schools created good opportunities to improve the teaching quality and school-running level. How to make full use of this brand-new standard to get the expected achievements requires an accurate mastery of the standards and systems with firmly established service awareness for 
providing high-quality products [3].

\subsection{Products}

ISO 9000 defines products as the results of activities and processes. There are always two different opinions on what school product is in academic circles. One view is that school products refer to training qualified students as the object, and products are the students [4]. Another point of view is that school is a mixture of the educational institutions, social institutions and economic entities. It is the basic form of education with economic attributes, while education is a service industry. Then school products are produced by using school places to carry out educational services, such as school curriculum, training base, teaching evaluation, etc. [5]. In this paper, school products refer to the provision of educational services. The product of education is different from the enterprise. It is vitality. The higher vocational colleges provide living facilities and learning equipment for students to help them improve their quality, increase their ability and enrich their knowledge. This educational service process is the product of school. The products of higher vocational colleges should have scientific location: market demand, innovation field and culture inheritance [6].

\subsection{Customers}

ISO9000 International Quality Management Standard describes customers as organizations and individuals that purchase products or require service objects. As college students pay tuition fees directly, obtain corresponding educational services and then increase their knowledge and talents. Accordingly, part of the expenses in higher vocational colleges also need the state to pay for running schools, which is an indirect payment of tuition. It can be seen that college students are customers of educational services in higher vocational colleges. The range of these customers includes college students, the state, social forces and other stakeholders. This is a consumption relation between higher vocational colleges and the organizations of college students, government and collaborators [7].

\subsection{Quality}

The definition of quality in ISO9000 is: the degree to which customers' needs is met. The quality of higher vocational colleges refers to the degree to which the inherent characteristics of educational services in higher vocational colleges meets the requirements of customers. The essence of educational quality is the degree to which the inherent characteristics in education, teaching, management and service meets the society's requirements for talents, students' development, students' life and safety. At present, in order to weaken the connection between family background and children's educational expectations, different individuals can have similar educational environment, the reasonable entry point is to narrow the quality difference between higher vocational colleges [8].

\section{Service Processes}

The quantity and quality of education services in China has made greater progress since the "13th Five-Year Plan" and the role of education in people's livelihood security has become more prominent. From the achievements and experiences in the implementation of the "13th Five-Year Plan", it is found that education services are facing new adjustments during the "13th Five-Year Plan". For example: AI, big data and digital humanities are embedded in the field of educational services. Wisdom, data and digital humanities education enriched the content of educational services and adapt to the country's changing development. At the same time, the educational objects and requirements of educational services will also undergo profound changes, so did the educational services in higher vocational colleges [9]. According to the annual report of quality data in higher vocational colleges from 2017 to 2019, the regional distribution of "Top 50 International Influential Colleges" shows a trend of concentration in some regions and provinces [10]. It can be seen that there is a long way to go on educational services of the "13th Five-Year Plan". Usually, not all activities in higher vocational colleges are educational services. Educational service is mainly focused on teaching activities which contains the process of education, teaching, management and service.

\subsection{Education Process}

Education process is different from logistics management and professional teaching in higher vocational colleges. It refers to the process of ideological, moral, health education and other activities for college students, such as: the second class, various theme education practical basement, artistic performances, sports competitions, college students' associations and other organizational activities, to cultivate the necessary character and key abilities for college students' lifelong development and social development, so as to meet the requirements of the country and society.

\subsection{Teaching Process}

Teaching process is the core of the educational service process in higher vocational colleges. It mainly refers to professional education, presented in the form of curriculum teaching, including a series of processes such as curriculum plan (customer requirements, teaching plan formulation, etc.), design, taking classes, counseling, exercises, examination and teaching feedback (homework analysis, examination analysis, etc.), etc. The functions of the teaching process include educating and developing people.

\subsection{Management Process}

Management process mainly refers to the daily management of college students, such as dormitory, catering and student status management, etc. The management process maintains the whole process of educational service in higher vocational colleges to promote the realization of educational goals smoothly. The integration of management and education 
process can not only provide students with specific knowledge and skills, but also good environment for learning and growth, to make sure that they are both "successful" and "healthy".

\subsection{Service Process}

The service processes and emphases are different in different higher vocational colleges. Service process refers to the process of providing learning and life services for college students. Including enrollment and employment promotion, reception of freshmen and organization of military training, dormitory meals, book information, security, graduation and leaving school services, etc.

\section{Management System}

Quality management of higher vocational colleges refers to the activities in which all staff participated in the designing, implementation, inspection and analysis of the work process and results of each department in higher vocational colleges, so as to achieve higher level achievements. According to the requirements of ISO9000 international quality management standard, the school's quality management system consists of four dimensions: senior management, resource management, service realization and monitoring measurement.

\subsection{Senior Management}

Senior Management Process is the process in which senior leaders perform the quality management functions, such as the short-term, medium-term and long-term development plans of the school; the quality of higher vocational colleges, such as teaching quality, civilization creation quality, post management quality, logistics support quality and other overall improvement policies and goals; the establishment of school's quality management leading group, quality management office, teaching department, service department and other quality management organizations, to ensure the smooth operation of the quality management system.

\subsection{Resource Management}

Resource management process refers to the process of organizing, coordinating, controlling and improving the manpower, infrastructure, working environment, information and other resources owned by the school to provide the material basis of the quality management system and ensure the efficient operation of different resource management. It is difficult to effectively manage the human resources owned by schools, especially the management of teachers' resources, such as professional growth, encouragement, teaching, etc. It is necessary to establish a scientific and reasonable human resources management system to supervise, in order to achieve the basic starting point and ultimate goal of teaching.

\subsection{Service Implementation}

Service realization process is the central process of quality management system. During the "13th Five-Year Plan" period, the focus on ensuring the quality of education is the management of the realization process of educational services. The education service of higher vocational colleges must verify the implementation plan before the implementation of the education service. In the process of management, it is necessary to pay special attention on the key points of quality management such as customer demand analysis, professional and instructional design, educational content and method design, teaching implementation, education and management implementation, and various service provisions.

\subsection{Monitoring Measurement}

Monitoring Measurement Process refers to the process of carrying out all-round, multi-angle and three-dimensional monitoring, measurement, analysis and improvement for the quality of higher vocational colleges. Among them, the educational service process is the focus of monitoring. The monitoring measurement process is the basis to ensure the continuous improvement of the first three processes. Schools should formulate comprehensive monitoring standards and establish a perfect monitoring system.

\section{Management Evaluation}

The evaluation of quality management in higher vocational colleges should start from four aspects: the Party quality performance evaluation, teaching units' work quality performance evaluation, functional departments' (directly affiliated units) work quality performance evaluation, teachers' teaching quality evaluation, etc., to improve service quality continuously.

\subsection{The Party Organizations' Work Quality}

The evaluation contents of the management quality of all Party branches and directly affiliated Party branches are the Party building work standard, work process, work performance, etc., which depend not only on the results but also the process. As shown in Table 1.

Table 1. Evaluation Index System of Party Building Work.

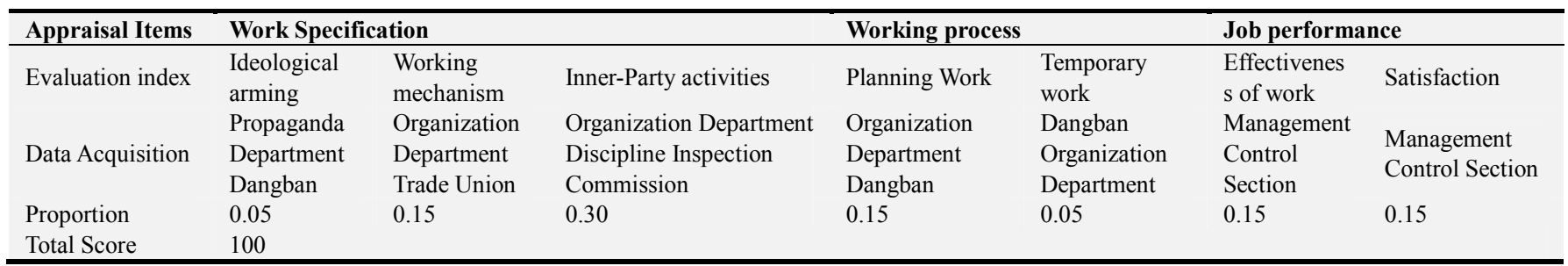


The evaluation of the work quality of all Party branches and directly affiliated Party branches is based on the evaluation index system of Party building work of grass-roots Party organizations (Table 1). A dynamic evaluation information network is established with a total score of 100 points through multiple channels and forms to collect evaluation information in a timely manner. At the end of the year, all Party branches and directly affiliated Party branches will conduct self-assessment according to their work conditions and submit the self-assessment report to the appraisers (data collectors). Each assessor in the school scores the quantitative part through hearing, seeing and evaluating. Each appraiser will submit the evaluation results to the school quality management office at the end of the year, and the management and monitoring department of the quality management office will be responsible for summarizing the scores. This department sorts and feeds back the scores of each Party organization [11]. If the evaluation score is above 75 points (including 75 points), the annual quality evaluation result is determined as "qualified" grade, and below 75 points, as "unqualified" grade. The annual quality evaluation score of the general branch of the United Party is the evaluation score of Party building work multiplied by 0.85 plus the average evaluation score of administrative work multiplied by 0.15 .

\subsection{The Teaching Units'Work Quality}

Teaching units' work quality performance evaluation consists of two parts: the evaluation of Party building work and the evaluation of administrative work. As shown in Table 2.

Table 2. Evaluation Index System of Administrative Work in Secondary Teaching Units.

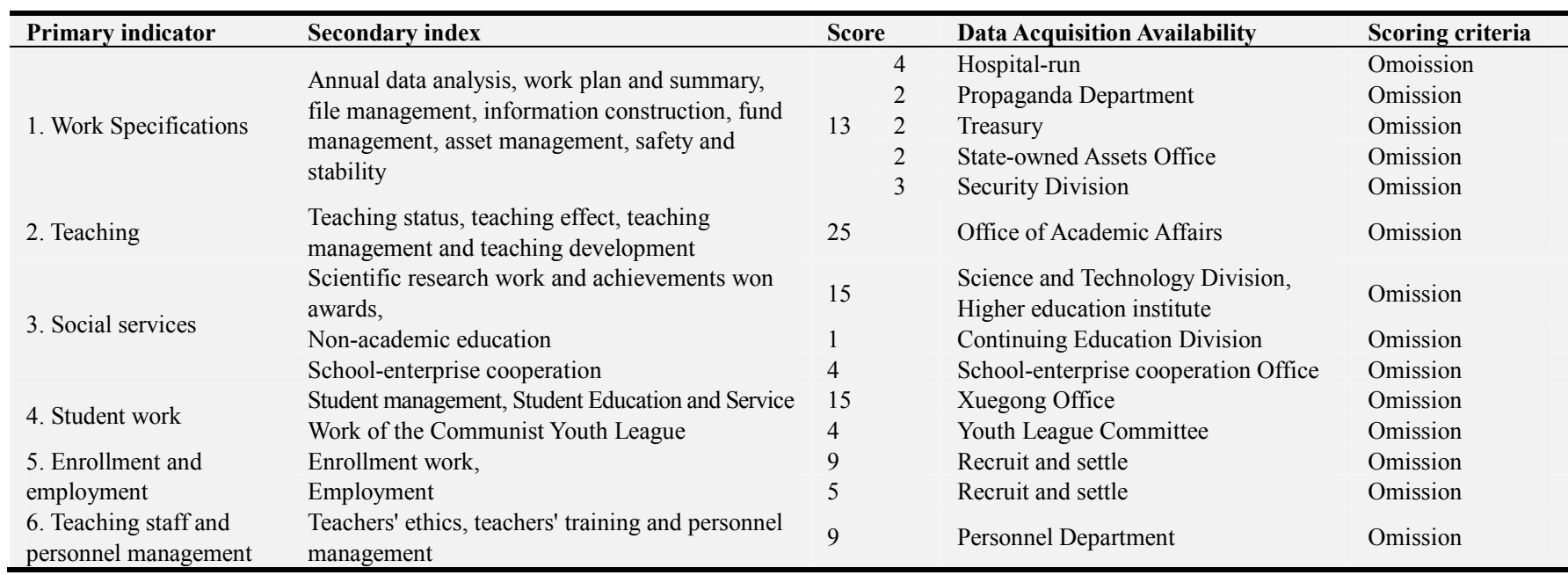

Teaching units' work quality performance evaluation is based on the "double-percentile" evaluation method of the evaluation index system of Party building work of grass-roots (Table 1) and administrative work of secondary teaching units (Table 2). A dynamic evaluation information network with a total score of 100 points each part is established through multiple channels and forms to collect evaluation information in time. Each unit shall conduct self-assessment according to the work situation at the end of the year and submit the self-assessment report to the appraiser (data collector). The content mainly includes the completion of the annual work, main achievements and innovative work. Each assessor in the school scores the quantitative part through hearing, seeing and evaluating. Each appraiser will submit the evaluation results to the school quality management office at the end of the year, and its department will be responsible for summarizing the scores. The department sorts and feeds back according to the annual quality evaluation score of secondary units (party building evaluation score multiplied by 0.3 plus administrative evaluation score multiplied by 0.7 ).

\subsection{The Functional Departments' Work Quality}

The evaluation of the functional departments consists of two parts: the evaluation of the Party building work and administrative work of departments. As shown in Table 3.

Table 3. Evaluation Index System of Department Administrative Work.

\begin{tabular}{|c|c|c|c|c|c|c|}
\hline Primary indicator & Secondary index & Data Acquisition & Scoring criteria & Proportion & \multicolumn{2}{|c|}{ Total Score } \\
\hline \multirow{7}{*}{$\begin{array}{l}\text { 1. Work } \\
\text { Specifications }\end{array}$} & 1. Mission objectives & Hospital-run & Omission & 0.06 & \multirow{7}{*}{20} & \multirow{7}{*}{100} \\
\hline & 2. File information & Propaganda Department, Hospital Office & Omission & 0.03 & & \\
\hline & 3. Labor discipline & Personnel Department & Omission & 0.02 & & \\
\hline & 4. Financial assets & $\begin{array}{l}\text { Finance Department, State-owned Assets } \\
\text { Department }\end{array}$ & Omission & 0.03 & & \\
\hline & 5. Security and stability & Security Division & Omission & 0.02 & & \\
\hline & 6. Building a clean government & $\begin{array}{l}\text { Discipline Inspection Commission and } \\
\text { Supervision Department }\end{array}$ & Omission & 0.02 & & \\
\hline & 7. Learning Research & Propaganda Department & Omission & 0.02 & & \\
\hline
\end{tabular}




\begin{tabular}{|c|c|c|c|c|c|}
\hline Primary indicator & Secondary index & Data Acquisition & Scoring criteria & Proportion & Total Score \\
\hline \multirow{3}{*}{ 2. Task } & 1. Routine work & \multirow{3}{*}{ Management Monitoring Section } & Omission & 0.35 & \multirow{3}{*}{60} \\
\hline & 2. Key work & & Omission & 0.20 & \\
\hline & 3. Innovation & & Omission & 0.05 & \\
\hline \multirow{4}{*}{$\begin{array}{l}\text { 3. Satisfaction } \\
\text { measurement }\end{array}$} & 1. Labor discipline & \multirow{4}{*}{ Management Monitoring Section } & Omission & 0.05 & \multirow{4}{*}{20} \\
\hline & 2. Service Attitude & & Omission & 0.05 & \\
\hline & 3. Efficiency & & Omission & 0.05 & \\
\hline & 4. Building a clean government & & Omission & 0.05 & \\
\hline
\end{tabular}

The evaluation is based on the "double-percentile" evaluation method of the grass-roots Party organization building work evaluation index system (Table 1) and the department administrative work evaluation index system (Table 3) of the general party branch where they are located. A dynamic evaluation information network with a total score of 100 points is established through multiple channels and forms to collect evaluation information in a timely manner. At the end of the year, each department conducts self-assessment according to its work situation and submits the self-assessment report to the appraiser (data collector). Each assessor in the school scores the quantitative part through hearing, seeing and evaluating. Each appraiser will submit the evaluation results to the school quality management office at the end of the year, and the department will be responsible for summarizing the scores. The department sorts and feeds back according to the department's annual quality evaluation score (the party building work evaluation score of the general party branch where it is located multiplied by 0.15 plus the administrative work evaluation score multiplied by 0.85 ). The evaluation score is above 75 points (including 75 points), the annual quality evaluation result is determined as "qualified" grade, and below 75 points as "unqualified" grade.

\subsection{The Teachers' Teaching Quality}

The construction of educational courses in higher vocational colleges should be market-oriented and meet the needs of serving the development of national economic construction and professionals training in colleges and universities [12]. The evaluation includes three aspects: teaching quality evaluation, teaching skill evaluation and teaching effect evaluation. The college's quality management office takes the lead in the overall assessment of the secondary teaching units, which are in charge of the assessment of the teaching staff in its department. Each secondary teaching unit shall set up a teaching quality assessment team, which may be composed of the leaders of their units, the heads of this sections (specialties), administrators, extramural experts, etc. The team leader shall be the heads of their units. The quality is evaluated online which composed of four parts: students' evaluation, peers' evaluation, secondary supervisions' evaluation, and members of the evaluation team. As shown in Table 4.

Table 4. Evaluation Index System of Teachers' Teaching Work.

\begin{tabular}{lllll}
\hline Evaluation method & Students' evaluation & Peers' evaluation & Supervision evaluation & Appraisal team evaluation \\
\hline Data Acquisition & Office of Academic Affairs & Each teaching and research section & Steering Team II & Level 2 Quality Evaluation Group \\
Proportion & 0.4 & 0.2 & 0.2 & 0.2 \\
Total Score & 100 & & & \\
\hline
\end{tabular}

Students' evaluation can be conducted online by all the students that the teacher taught. Peers' evaluation can be conducted online by the teacher's teaching and research section or professional colleagues. The secondary supervisions' evaluation can be conducted online by $10 \%$ of full-time teachers after listening to lectures. The evaluation of members in this team can be conducted online by members of the assessment team after reviewing relevant materials. Among them, students' evaluation is a mandatory option, and the evaluation score must account for more than $40 \%$ of the total score in teachers' semester teaching quality assessment. When construct this evaluation system, the school should combine the actual situation of different students, start from their specific life content. The evaluation should divide into two parts: students' learning behavior evaluation and life behavior evaluation to take students' future development as the foothold, and pay attention to the evaluation process, humanism and scientific system consciousness [13]. Whether other evaluation methods are selected or not can be determined by the teaching quality evaluation team of each secondary teaching unit. The team should formulate detailed rules for the assessment, complete all the department's full-time and part-time teachers' semester and annual teaching quality assessment, check the teachers' assessment results, and deal with the problems appeared in the assessment. Teachers' teaching quality assessment includes: two semesters' assessment and annual assessment. The semester assessment is a comprehensive score, and the annual is the ranking in the unit. The annual ranking of the assessment is determined according to the average ranking of assessment scores of two semesters. For teachers who undertake teaching tasks in two semesters of the same year, the academic year evaluation result is the two semesters' average score. In addition, to improve the awareness of school quality, including scientific evaluation, students' performance, etc., the school's evaluation method should change from results to processes, emphasize using data to get the focus, cultivate bottom-up "Spontaneous" school change ability, take school improvement as the main starting point to improve school quality [14].

\section{Conclusion}

Survival and success are strived by quality. Higher 
vocational colleges should scientifically formulate the relevant contents of education services in the "14th Five-Year Plan", keep research mind on the quality management system in higher vocational colleges, combine the facts of each school, use combination strategy, and make plans based on strategic research to realize the combination of elements in higher vocational colleges. At the same time, under the background of the "14th Five-Year Plan", the quality management system's practical exploration should reflect equality and inclusiveness in concept, aim at promoting high-quality educational resources in content, create a new era of intelligent education space in service, to build an efficient and scientific quality management and evaluation system in higher vocational colleges. If higher vocational colleges want to develop sustainably with competitive advantages, they must stand at the high point of management, improve the management quality continuously, and strive to shape the quality culture.

\section{Acknowledgements}

This project was sponsored by Vocational Education Development Research Center of Zigong Philosophy and Social Science Research Base (\#ZYJY20-01).

\section{References}

[1] Sun Li. Reconstruction and Discrimination in the Definition of School Quality [J]. Journal of Liaoning Institute of Education Administration, 2016 (6): 50-52.

[2] Zhou Yingzhong. Cultivation and Generation of Quality Culture: the core path of high-level construction in higher vocational schools [J]. China Higher Education Research, 2020 (3): 98-101

[3] Shu Nengyi. Schools' Products, Customers and Related Issues of in ISO9000 Quality Management System [J]. China Vocational and Technical Education, 2007 (20): 20-21 +23.
[4] Wang Shanmai. Research on Educational Input and Output [M]. Shijiazhuang: Hebei Education Press, 1996: 12.

[5] Chen Xiao-yu. On the Product Attributes of Education and Profitable Schools [J]. Tsinghua University Educational Research, 2012 (1): 109-116.

[6] Chen Bailin. The Necessity, Reality and Necessity of Dislocation Development of Higher Vocational Colleges in China [J]. Education and Occupation, 2020 (22): 46-51.

[7] Liu Xiaohuan. Quality Management System of Higher Vocational Colleges under the Framework of ISO9000 Standard [J]. Vocational Education Forum, 2005 (31): 13-16.

[8] Jin Zhenzhong, Yan Binjian, Wang Liang. Family Background, School Quality and Children's Educational Expectations-An Analysis Based on China's Educational Tracking Survey [J]. Educational Research, 2019 (12): 107-121.

[9] Shan Dasheng, Yang Yinfu. Development Prospect of Educational Service during the 14th Five-Year Plan period [J]. China Journal of Education, 2020 (6): 50-55.

[10] $\mathrm{Su} \mathrm{Li,} \mathrm{Hong} \mathrm{Lv.} \mathrm{International} \mathrm{Influence} \mathrm{of} \mathrm{Higher} \mathrm{Vocational}$ Colleges: Characteristics and Countermeasures-Based on Visual Analysis of Quality Annual Report Data of "Top 50 International Influence" Higher Vocational Colleges in Recent Three Years [J]. China Vocational and Technical Education, 2020 (30): 48-54.

[11] Yang Qiliang. Evaluation for Teaching and Teaching for Evaluation [J]. Educational Research, 2012 (7): 98-103.

[12] Wu Liquan, Liu Lingzhi. Practice and Exploration on the Quality Monitoring and Evaluation System of Innovation and Entrepreneurship Education [J]. Heilongjiang Animal Husbandry and Veterinary, 2020 (2): 144-146.

[13] Li Meixia. The Construction of the Evaluation System of Students' Behavior Development in Boarding Schools [J]. Teaching and Management, 2020 (12): 66-68.

[14] Wang Jingying, Zhang Mengyang, Li Yanyan. How to Improve the Quality of Schools-Based on a mixed study of 25 primary and secondary school principals [J]. Research on Educational Development, 2019 (2): 54-60. 